\title{
A case of Buschke-Lowenstein tumor with hypogastric extension
}

\author{
Kaoutar Sof ${ }^{1}$, Hanane Daflaoui'1, Soraya Aouali', Siham Dikhaye ${ }^{2}$, Nada Zizi² \\ ${ }^{1}$ Department of Dermatology, Mohammed 6 University Hospital of Oujda - Medical School of Oujda, Mohammed First \\ University of Oujda, Morocco, ${ }^{2}$ Laboratory of Epidemiology, Clinical research and Public Health, Medical School of Oujda, \\ Mohammed First University of Oujda, Morocco
}

Corresponding author: Dr. Kaoutar Sof, E-mail: kaouthar.sof@gmail.com

\begin{abstract}
The giant condyloma acuminatum or Buschke-Löwenstein tumor (BLT), is a rare sexually-transmitted disease. The BLT is caused by human papillomavirus (HPV) which affect the perineal region. BLT is an anogenital tumor with histologically benign aspect but it has an invasive growth and a potential of malignant transformation. The first therapeutic option is surgical excision. We report the case of a 61-year male with a BLT developing since 10 years and extending to the hypogastric region.
\end{abstract}

Key words: Condyloma; Buschke-Löwenstein; HPV; Hypogastric

\section{INTRODUCTION}

Giant condyloma acuminata, also known by the eponym Buschke-Lowenstein tumor (BLT), is a human papillomavirus (HPV) -associated verrucous carcinoma of the anogenital region [1]. BLT is a rare sexuallytransmitted disease (STD) [2], with an incidence of approximately $0.1 \%$ in the general population [3], whose main risk factor is the infection with the Human Papilloma Virus (HPV) [4]. BLT is characterized by an invasive growth, a high rate of recurrence to the treatment and likely potential of malignant transformation (squamous cell adenocarcinoma) [2]. Since this disease is rare and no controlled studies exist, radical excision of this anogenital lesion is generally recommended as the first line therapy and close vigilance and follow-up are essential [5].

\section{CASE REPORT}

A 61-year-old man presented to the emergency department complaining of perineo-scrotal tumor. It had initially started as a small condyloma that gradually grew over 10 years. Our patient was heterosexual, with the notion of unprotected sex. He reported no fevers, loss of weight, urinary symptoms, or difficulty in defecation. The pathological history of the patient did not reveal chronic diseases or the administration of some medications which might have suppressed the function of the immune system. The Dermatology Life Quality Index was at 14 reflecting a significant effect on patient's quality of life, with important repercussion on his sexual life.

The clinical examination revealed multiple irregular exophytic verrucous fetid tumors, of variable size from $3 \mathrm{~mm}$ to $10 \mathrm{~cm}$, with some stony and hard consistency areas (cauliflower-like), covering the whole perineum and hypogastrium (Fig. 1), extending to the perianal region and the interfessier furrow (Fig. 2). The local superficial lymph nodes could not be found at palpation.

The laboratory tests reveal severe microcytic, hypochromic anemia with a haemoglobin value of $5.7 \mathrm{~g} / \mathrm{dl}$, while the rest of investigation was normal. The patient receives blood transfusions, eventually the haemoglobin reaching a value of $10.16 \mathrm{~g} / \mathrm{dl}$, close to its normal value $(12 \mathrm{~g} / \mathrm{dl})$.

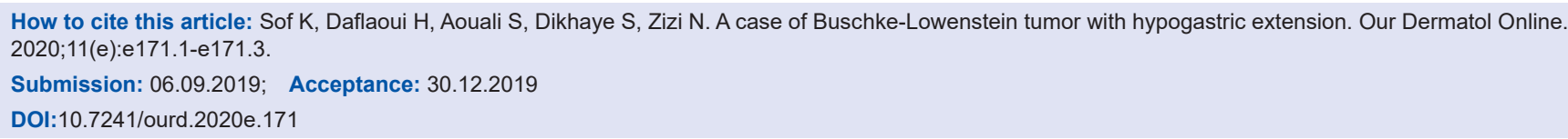




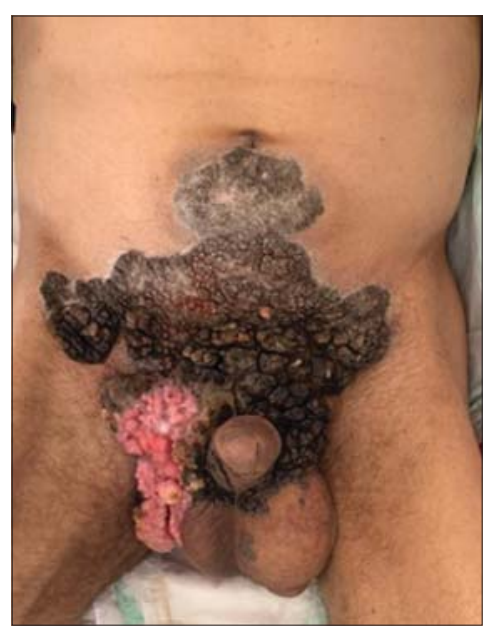

Figure 1: Anterior view: perineal involvement with hypogastric extension.

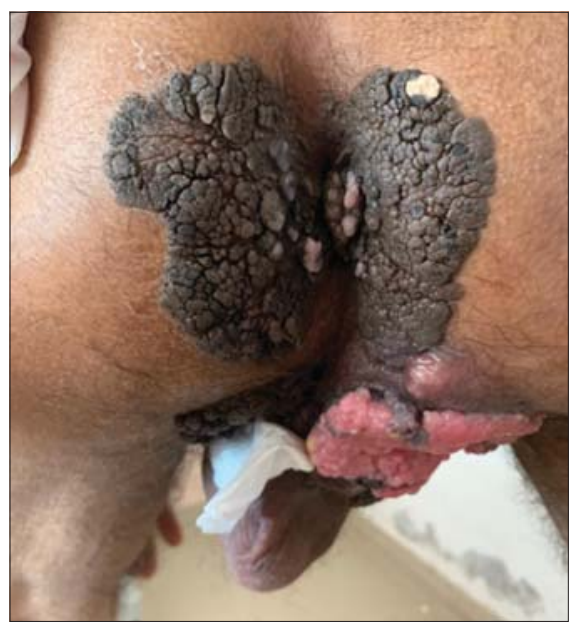

Figure 2: Posterior view showing the perineo-anal extension.

HIV, syphilis, and hepatitis B and C tests were negative. Colonoscopy examination did not show any extension at the rectal mucosa and magnetic resonance imaging was without abnormality.

Histological examination of a biopsy specimen revealed an exophytic epithelial proliferation, made of thick epithelial vegetations, surmounted by a thick layer of parakeratotic cells, with the presence of koilocytes, signs of HPV infection, Cellular atypia was not detected.

The diagnosis of Buschke-Löwenstein tumor was retained and the patient was referred to the urological surgery for extensive excision.

\section{DISCUSSION}

The Buschke-Löwenstein tumor (BLT) or giant condyloma is an epithelial tumor described by
Buschke and Löwenstein in 1925 [6]. It differs from an acuminated condyloma by its size, its potential for repression of neighboring tissues and the risk of transformation into invasive epidermoid carcinoma.

The TBL is inconsistently associated with human papillomavirus (HPV) infection, most often nononcogenic: HPV 6 and 11 [7].

Despite its indolent nature and its low degenerative power, the BLT significantly alters the patient's quality of life and especially his sexual life by its large size as is the case with our patient; indeed the hypogastric extension has never been described in the literature before.

Because of the rarity of this tumor, the optimal management strategy is not known at this time. Chemoradiation has been recommended in cases when malignant transformation may occur [8]. Intraarterial chemotherapy with agents such as methotrexate has also been successfully utilized in verrucous carcinoma of different parts of the body, including the anogenital region. This modality may be used as neoadjuvant therapy before surgical intervention and in certain cases may obviate the need for surgery. Radiation therapy alone has generally been discouraged because of potential risk of transformation into anaplastic carcinoma $[9,10]$.

The risk of mortality, evaluated at $21 \%$ in perianal TBL but unknown in penoscrotal TBL, it is caused by the local invasion and the slow destruction of the underlying tissues [7].

\section{CONCLUSION}

The delay of consulting a doctor can increase the risk of malignant degeneration and the possibility of a huge tumor growth. This can lead to compressive and infectious complications, making treatment more difficult.

Prevention is the only effective treatment consisting on sex education and early treatment of condylomatous lesions.

\section{Consent}

The examination of the patient was conducted according to the Declaration of Helsinki principles. 


\section{www.odermatol.com}

The authors certify that they have obtained all appropriate patient consent forms. In the form the patient(s) has/have given his/her/ their consent for his/her/their images and other clinical information to be reported in the journal. The patients understand that their names and initials will not be published and due efforts will be made to conceal their identity, but anonymity cannot be guaranteed.

\section{REFERENCES}

1. Bowman IA, Parra A, Arriaga Y. Metastatic Giant Condyloma Acuminata (Buschke-Löwenstein Tumor). J Oncol Pract. 2016;12:951-3

2. Sandhu R, Min Z, Bhanot N. A gigantic anogenital lesion: BuschkeLowenstein tumor. Case Rep Dermatol Med. 2014;2014:650714.

3. Sandoval I, Hernández R, Torres E, Yanque O. Giant condylomata acuminata of Buschke-Lowenstein. J Obstet Gynaecol. 2020;40:582-3.

4. Gürbulak EK, Akgün İE, Ömeroğlu S, Öz A. Giant perianal condyloma acuminatum: Reconstruction with bilateral gluteal fasciocutaneous V-Y advancement flap. Ulus Cerrahi Derg.
2015;31:170-3.

5. Yuksel ME, Tamer F. A giant skin tag of the scrotum and verruca anogenitalis. Our Dermatol Online. 2017;8:239-40.

6. Buschke A, Lowenstein L. Uber carcinomahnliche Condylomata Acuminata des Penis. Klin Wochenschr 1925;4:1726-8.

7. Dauendorffer JN, Cavelier-Balloy B, Bagot M, Renaud-Vilmer C. [Male genital Buschke-Löwenstein tumour]. Ann Dermatol Venereol. 2016;143:796-8.

8. Fai EK, Bhutta HA, Ali K. Progression of a Buschke-Lowenstein tumor into invasive squamous cell carcinoma. JAAPA. 2019;32:1-4.

9. Chiang $\mathrm{PH}$, Chen $\mathrm{CH}$, Shen YC. Intraarterial chemotherapy as the first-line therapy in penile cancer. Br J Cancer. 2014;111:1089-94.

10. Nassiri A, Aqil N, Baybay H, Mernissi FZ, Souhli OA, Ahssaini M, et al. Extra genital HPV-6. Our Dermatol Online. 2019;10:71-3.

Copyright by Kaoutar Sof, et al. This is an open-access article distributed under the terms of the Creative Commons Attribution License, which permits unrestricted use, distribution, and reproduction in any medium, provided the original author and source are credited.

Source of Support: Nil, Conflict of Interest: None declared. 